\title{
Community Knowledge towards Zoonotic Diseases and Attitude to One Health Approach in selected City of Ethiopia
}

\section{Adem Hiko*, Bezaneh Yilkale and Biressaw Serda}

College of Veterinary Medicine, Haramaya University, Dire Dawa, Ethiopia

*Corresponding author: Adem Hiko, College of Veterinary Medicine, Haramaya University, Dire Dawa, Ethiopia, Tel: +251940240080; E-mail: adex.2010ph@gmail.com Received date: September 24, 2018; Accepted date: September 28, 2018; Published date: October 05, 2018

Copyright: @ 2018 Hiko A, et al. This is an open-access article distributed under the terms of the Creative Commons Attribution License, which permits unrestricted use, distribution, and reproduction in any medium, provided the original author and source are credited.

\begin{abstract}
Background: Zoonotic diseases are substantial global public health burden from the risk linked among humans, animal populations and the surrounding environment as "One Health" issue.

Objective: This study was aimed to assess community knowledge on selected zoonotic diseases and attitude towards One Health approach in and around Bahir Dar City, Ethiopia.

Methodology: simple random sampling technique. Interview was used to collect community knowledge on selected zoonosis and attitude towards One Health approach. For responses given, a score of 1 was given for each knowledgeable and positive attitude response and 0 for unsure responses.

Results: The majority (84.2\%) were knowledgeable on rabies as viral zoonosis. Almost similar, $30.2 \%, 29.9 \%$ and $12.6 \%$ of participants were knowledgeable about bovine tuberculosis, anthrax and brucellosis from bacterial zoonosis in descending order. Again $36.1 \%, 18.3 \%$ and $17.7 \%$ of participants were knowledgeable about taeniasis, manage and echinococcosis from parasitic zononosis respectively. Only $26.0 \%$ were awarded ring worm from fungal zoonosis. Very few (8.7\%) awarded bovine mastitis from multifactorial zoonosis. Significantly higher (84.2\%; $\mathrm{OR}=56.0 ; 95 \%$ OR $\mathrm{Cl}=36.2-86.9)$ are knowledgeable about zoonotic risk of rabies compared to other assessed disease. However, the majorities (78.47\%) of the respondents had positive attitude towards One Health approach for collaboration activities of health sectors but the remaining $21.53 \%$ were not. Similarity in community attitudes towards One Health approach were observed within age categories $(p=0.454)$ but significant differences were observed between gender $(p=0.023)$, among education status $(p=0.001)$ and among the professional profiles $(p=0.001)$ of studies population.
\end{abstract}

Conclusion: The result calls for organized outreach One Health approach based community education and awareness creation on the knowledge, associated risk factors of zoonotic disease.

Keywords: Bahir dar; Community; Knowledge; One health; Zoonosis

\section{Introduction}

Zoonotic diseases are posing a great infliction on substantial global public health burden [1] and also lead to economic losses, in terms of the cost of treatment, cost of agriculture characterized by low livestock production [2,3]. Out of about 1415 species considered as pathogenic agents to humans recorded in the year 2001, about 868 (61\%) may possibly be categorized as zoonotic, and $75 \%$ of them are known to be emerging [3-5]. The link among humans, animal populations and the surrounding environment is very close in many developing countries, where animals provide transportation, draught power, fuel, clothing and sources of protein (that is, meat, eggs, and milk) [3-6]. Here, the absence of proper care for such animals lead pathogen shading from stress induced by prolonged transportation, confinement, crowding, and increased handling [7]. In most of the developing countries, human practice of poor sanitation and open defecation [8], backyard slaughter, the tradition of consuming raw milk [6] and raw or under cooked meat [9], poor implementation of food safety regulations and risk-based food safety systems [10], poorly equipped food processing plants and slaughterhouses, lack of awareness about food borne and zoonotic diseases in the society [8], and lack of food storage facilities such as refrigeration, due to poor electricity coverage and unaffordable prices [9] complicated the situation [11].

Know a days, international community came across the forgotten "concept of One Health" [1] as a remedy for zoonosis control. The concept requires strong multidisciplinary and multi-sector collaboration, and this goes above veterinary public health systems strengthening to better clear disease prevention [12], having safer food production as emphasis, sustainable animal agriculture adoptions, distribution and marketing and management of natural resource [1,13-15] through prevention and control of zoonosis and emerging dioceses by surveillance, identification, investigation and mitigation action $[12,14]$.

Understanding the awareness and knowledge of community on zoonosis and One Health approach attitude encompasses accurate and timely dissemination of the information on the diseases $[16,17]$. Thus, only few studies on the awareness of community on few zoonotic diseases, the associated risk factors and veterinary public health in Ethiopia [8,18-22] were conducted. But, community knowledge on zoonosis in Bahir Dar City and attitude on One Health approach were 
not yet assessed in Ethiopia including in Bahr Dar. Therefore, the aim of this study was to assess community knowledge on selected categories of zoonosis and attitude on One Health approach in and around Bahir Dar City, North Ethiopia.

\section{Materials and Methods}

\section{Ethical approval}

Interview of human beings on the knowledge of zoonosis and attitude towards One Health approach were made in this study. Thus, ethical clearance was obtained from College of Veterinary Medicine, Haramaya University Ethical Committee. Information was kept confidential. Informed consent was obtained from the participants. Post interview, scientific based risk of zoonosis and contribution of One Health in the livelihood were introduced to participants.

\section{Description of the study area}

Study was conduct in and around Bahir Dar city, the capital city of the Amhara Regional State, located at about $565 \mathrm{Km}$ North West of Addis Ababa Capital City-Ethiopia. The area is found at an elevation ranging from 2276 to 1660 meter above sea level in between $11^{\circ} 27^{\prime}$ 1.82 to $11^{\circ} 39^{\prime} 7.56 \mathrm{~N}$ and $37^{\circ} 16^{\prime} 36.75 \mathrm{E}$ to $37^{\circ} 31^{\prime} 48.06 \mathrm{E}$. It has summer rainfall with the highest rainfall from June to September and a winter dry season (December to March). The mean annual rainfall is $1200-1600 \mathrm{~mm}$, and means temperature $10-20^{\circ} \mathrm{C}$ [23]. Based on the 2007 Census conducted by the Central Statistical Agency of Ethiopia [24], Bahir Dar Special Zone has a total population of 221,991 of whom 108,456 are men and 113,535 women. The majorities, 180,174 $(81.16 \%)$ are urban inhabitants but the rest living at rural Kebeles around Bahir Dar.

\section{Study design}

A questionnaire based cross-sectional study was designed and employed during assessment. A semi-structured pre tested questionnaire was used for the face-to-face interview.

\section{Study population}

The study populations were residents of Bahir Dar City and its surrounding Kebeles. Thus, the farmers, butchers, teachers, students, office workers, merchants, health workers, veterinary workers and restaurant workers were incorporated regardless of age, gender educational statues and occupation.

\section{Sample size determination}

The desired sample size was estimated by expecting $50 \%$ of population could be knowledgeable about zoonotic disease and have positive attitude towards One Health approach. Thus, the sample size was calculated according to Thrusfeild [25] using 95\% confidence interval and 0.05 absolute precision. The desired sample size becomes 384 where $5 \%$ were added in case of some may fail to responded. The final sample was 404 individuals.

\section{Data collection methodology}

The questionnaire were first developed in English and then translated in to the local language (Amharic- the native language in the Amhara Region-Ethiopia) for appropriateness and easiness in approaching the study participants. On average, 10 minutes were spent with each respondent. The questionnaire contains questions that can evaluate demographic characteristics (age, gender, education level, profession and occupation). Accordingly, farmers, butchers, teachers, students, office workers, merchants, health workers, veterinary workers and restaurant workers were included in the study. The farmers included in the study are found in the villages around Bahir Dar city and practice the mixed crop-livestock production system.

\section{Data management and analysis}

The data was collected, coded and entered into a spread Excel $2013^{\circ}$ sheet. Percentages were calculated using SPSS Version 20. Chi square and p-value were also calculated. Odds ratio (OR) and OR 95\% Confidence intervals (CI) were also calculated using Win Pepi Version 11.5 and considered to represent a significant difference.

\section{Results}

\section{Community knowledge on specific categories of zoonotic diseases}

The majority (84.2\%) were knowledgeable on rabies as viral zoonosis. Low and almost similar, $30.2 \%, 29.9 \%$ and $12.6 \%$ of participants were knowledgeable about bovine tuberculosis, anthrax and brucellosis from bacterial zoonosis in descending order. Again $36.1 \%, 18.3 \%$ and $17.7 \%$ of participants were knowledgeable about taeniasis, manage and echinococcosis from parasitic zononosis respectively. Only $26.0 \%$ were awarded ring worm from fungal zoonosis. Very few $(8.7 \%)$ awarded bovine mastitis from multifactorial causal zoonosis. Significantly higher population $(84.2 \%, \mathrm{OR}=56$; $95 \% \mathrm{OR} \mathrm{CI}=36.2-86.9$ ) are knowledgeable about zoonotic risk of rabies compared to other assessed disease like taeniasis $(36.1 \%$, OR=6.0; 95\%OR CI=4.0-9.0), ring worm (26.0\%; OR=3.7; 95\%OR CI=2.5-5.6) and mastitis (8.7\%; OR=1; 95\%OR CI=0.6-1.6) (Table 1).

\begin{tabular}{|c|c|c|c|c|}
\hline Zoonotic diseases categories & Specific diseases & No. $(\%)$ of Knowledgeable community on Zoonotic diseases $(\mathrm{N}=404)$ & OR & $95 \%$ OR Cl* \\
\hline Viral Diseases & Rabies & $340(84.2)$ & 56 & $36.2-86.9^{c}$ \\
\hline \multirow{3}{*}{ Bacterial Diseases } & Anthrax & $121(29.9)$ & 4.5 & $3.0-6.8^{b}$ \\
\hline & Tuberculosis & $122(30.2)$ & 4.6 & $3.2-6.9^{b}$ \\
\hline & Brucellosis & $51(12.6)$ & 1.5 & $0.9-2.5 \mathrm{ab}$ \\
\hline
\end{tabular}


Citation: Hiko A, Yilkale B, Serda B (2018) Community Knowledge towards Zoonotic Diseases and Attitude to One Health Approach in selected City of Ethiopia . J Health Educ Res Dev 6: 276. doi:10.4172/2380-5439.1000276

Page 3 of 5

\begin{tabular}{|l|l|l|l|l|}
\hline \multirow{3}{*}{ Parasitic Diseases } & Taeniasis & $146(36.1)$ & $4.0-9.0^{\mathrm{b}}$ \\
\cline { 2 - 6 } & Echinococcosis & $71(17.7)$ & $7.5-3.5^{\mathrm{a} \mathrm{b}}$ \\
\cline { 2 - 5 } & Mange & $74(18.3)$ & $1.5-3.7^{\mathrm{ab}}$ \\
\hline Fungal zoonosis & Ring worm & $105(26.0)$ & 2.3 & 2.4 \\
\hline Multifactorial diseases & Mastitis & $35(8.7)$ & 3.7 & $2.5 .6^{\mathrm{b}}$ \\
\hline
\end{tabular}

Table 1: Community Knowledge on specific categories of zoonotic diseases interviewed. Note: ${ }^{*}$ is significantly higher than ${ }^{b}$ and ${ }^{a}$; ${ }^{b}$ is significantly higher than ${ }^{\mathrm{a}}$.

\section{Community attitude toward one health approach}

Community attitude toward One Health approach was indicated in Table 2. The majorities (78.47\%) of the respondents had positive attitude towards cooperative working of veterinarians and human health workers. There is significant difference $(\mathrm{P}<0.05)$ between the attitude of community towards One Health approach between gender, among educational status and among professions but no $(\mathrm{p}>0.05)$ among age groups.

\begin{tabular}{|c|c|c|c|c|c|c|}
\hline \multicolumn{2}{|c|}{ Demography of the respondents } & \multirow{2}{*}{$\begin{array}{l}\text { Total Interviewed } \\
25\end{array}$} & \multicolumn{2}{|c|}{ Attitude of community on One Health Program } & \multirow{2}{*}{$\mathrm{x}^{2}$} & P. value \\
\hline \multirow[b]{8}{*}{ Age } & $15-20$ & & \begin{tabular}{|l|} 
Present No. (\%) \\
$18(72.0)$ \\
\end{tabular} & $\begin{array}{l}\text { Absent No. (\%) } \\
7(28.0)\end{array}$ & & \multirow{8}{*}{0.454} \\
\hline & $21-25$ & 129 & $95(73.64)$ & $34(26.36)$ & \multirow{7}{*}{6.75} & \\
\hline & $26-30$ & 119 & $93(78.15)$ & $26(21.85)$ & & \\
\hline & $31-35$ & 49 & $40(81.63)$ & $9(18.37)$ & & \\
\hline & $36-40$ & 36 & $30(83.33)$ & $6(16.67)$ & & \\
\hline & $41-45$ & 22 & 20(90.91) & $2(9.09)$ & & \\
\hline & $46-50$ & 13 & $12(92.31)$ & $1(7.69)$ & & \\
\hline & $>50$ & 11 & $9(81.82)$ & $2(18.18)$ & & \\
\hline \multirow{4}{*}{ Gender } & \multirow{2}{*}{ Male } & 23 & \multirow{2}{*}{$196(82.35)$} & \multirow{2}{*}{$42(17.65)$} & \multirow{4}{*}{5.18} & \multirow{4}{*}{0.023} \\
\hline & & 8 & & & & \\
\hline & \multirow{2}{*}{ Female } & 16 & \multirow{2}{*}{$121(72.89)$} & \multirow{2}{*}{$45(27.11)$} & & \\
\hline & & 6 & & & & \\
\hline \multirow{6}{*}{$\begin{array}{l}\text { Educational } \\
\text { status }\end{array}$} & Illiterate & 28 & $16(57.10)$ & $12(42.90)$ & \multirow{2}{*}{41.88} & \multirow{2}{*}{0.001} \\
\hline & (1-8 class $)$ & 73 & $43(58.90)$ & $30(41.10)$ & & \\
\hline & (9-12 class) & 65 & $47(72.30)$ & $18(27.70)$ & & \\
\hline & College & 125 & $107(85.60)$ & $18(14.40)$ & & \\
\hline & First Degree & 106 & $97(91.50)$ & $9(8.50)$ & & \\
\hline & Above & 7 & $7(100.00)$ & $0(0.00)$ & & \\
\hline \multirow{5}{*}{ Profession } & Farmer & 60 & $33(55.00)$ & $27(45.00)$ & \multirow{5}{*}{42.07} & \multirow{5}{*}{0.001} \\
\hline & Merchant & 37 & $26(70.30)$ & $11(29.70)$ & & \\
\hline & Student & 42 & $35(83.30)$ & $7(16.70)$ & & \\
\hline & Teacher & 52 & $48(92.31)$ & $4(7.69)$ & & \\
\hline & Medical professionals & 41 & $38(92.70)$ & $3(7.30)$ & & \\
\hline
\end{tabular}




\begin{tabular}{|l|l|l|l|l|l|}
\hline \multirow{5}{*}{} & Restaurant workers & 46 & $34(73.90)$ & $12(26.10)$ & \\
\cline { 2 - 6 } & Office workers & 47 & $36(76.60)$ & $11(23.4)$ \\
\cline { 2 - 6 } & Butcher men & 42 & $31(73.81)$ & $11(26.20)$ \\
\cline { 2 - 6 } & Veterinary professionals & 37 & $36(97.30)$ & $4(10.81)$ & \\
\hline \multirow{2}{*}{ Total } & & 40 & $317(78.47)$ & $87(21.53)$ & \\
\cline { 2 - 7 } & & 4 & & \\
\hline
\end{tabular}

Table 2: Community attitude on One Health Approach (Medico-Veterinary collaboration)" by demography.

\section{Discussion}

The impact of public health veterinarians felt globally in the areas of creating awareness and education of zoonoses to the general public, prevention, investigations of infectious disease outbreak, food safety and protection, investigations of foodborne diseases, occupational exposure, and environmental health issue [26,27]. From present finding, the degree of community knowledge/perception towards categories zoonotic diseases was found quite different for each of specific zoonotic disease. The majority of the respondents knew and aware of rabies $(84.16 \%)$ which is similar with $100 \%$ the reports of Girma et al. [18], (88.7\%) report of Chikerema et al. [28], 97.1\% report of Tesfaye et al. [20] and 94.7\% report of Tirsit et al. [21] in different parts of Ethiopia. This could be due to frequent prevalence of rabies in developing countries [29-31] from which the community was award. Unlike the report of Girma et al. [18] on anthrax (94.27\%), taeniasis (89.06\%), bovine tuberculosis $(88.54 \%)$ and brucellosis $(49.48 \%)$ community awareness in Addis Ababa City, low number of community were aware of anthrax (29.95\%), taeniasis (36.14\%), bovine tuberculosis $(30.20 \%)$ and brucellosis $(12.62 \%)$ respectively in Bahir Dar. The present findings were also lower than the reports of Tesfaye et al. [20] on Taeniasis (83.4\%) and anthrax (55.4\%) in Jimma. On the other hand similar findings were reported by Chikerema et al. [28] on brucellosis (20.9\%), Tesfaye et al. [20] on bovine tuberculosis $(29.1 \%)$ and Tirsit et al. [21] on brucellosis (29.2\%). The present knowledgeable community level on echinococcosis (17.57\%) were higher than the reports of Tesfaye et al. [20] on Hydatidosis (4\%) but lower than the reports of Tirsit et al. [21] hydatidosis (68.6\%). Likewise, we found only low number of knowledgeable community on other zoonotice diseases like ringworm (25.99\%), mange (18.32\%), and mastitis (8.66\%) in this study. This variation among community knowledge of different zoonotic diseases could be due to difference between the community living standard, educational level, communication, exposers and training between and among locations in Ethiopia. Thus, zoonotic diseases remain a great threat to the health of the general public and paramount to greater economic losses both in area. Snedeker et al. [2] also reported the case the developing and developed countries. Other study also indicates that many infections and deaths from zoonotic diseases results from absence of awareness [32].

The One Health initiative in the community is dedicated to improving the health of all species- both human and animal through the integration of primary health care $[32,33]$ to improve human, environmental, and animal health [34]. If this fails, serious public health risks (zoonoses) with huge economic consequences often result when the animal-human link is poorly managed [34,35]. In many countries, collections of the animal and human data relating to zoonoses are carried out quite independently and with predictably unsatisfactory outcomes [36]. In this study, the attitude of respondents about the cooperative working of veterinarians and human health in the form of One Health approach were almost positive 317 (78.7\%). Except for low level of illiterate (57.1\%), class [1-8 educated individuals] (58.9\%) and farmers (55.0\%), the majorities (i.e., regardless of age, gender, education and profession) greater than $70 \%$ of intervened community have positive attitude towards One Health approach of control and prevention of zoonosis. This indicated the positive role and future need of the approach from grass root level within community.

\section{Conclusions}

Except for rabies, community knowledge on common categories zoonotic diseases was found low. Awareness should be created among the public in Ethiopia through education on the associated risk, preventive method and control measures for the implementation of One Health approach. Thus, sustainable collaboration between veterinary, human and environmental health care, with also including plant health, professionals were considered to be important and paramount to combat those diseases.

\section{Authors' Contributions}

$\mathrm{AH}$ : Imitate the concept, develop proposal, prepared question, collect data, analysis, reference search, and editing manuscript writing; BA: Study conduction, collect data, data entry and reference search. Both authors write manuscript and have read and approved the final version.

\section{Acknowledgments}

We would like to thanks the Bahir Dar community for their willingness and time value spent in providing all relevant information which enriches this finding.

\section{Computing Interests}

The authors declare that they have no competing interests.

\section{References}

1. World Bank (2012) People, Pathogens and Our Planet: The Economics of One Health [e]. The World Bank 11892.

2. Snedeker KG, Anderson MEC, Sargeant JM, Weese JS (2013) A Survey of Canadian Public Health Personnel Regarding Knowledge, Practice and Education of Zoonotic Diseases. Zoonoses and Public Health 60: 519-525. 
3. Halsby KD, Walsh AL, Smith R, Said B, Kirkbride H, et al. (2014) The Health Burden of Orphan Zoonotic Disease in the United Kingdom. Zoonoses and Public Health 61: 39-47.

4. $\quad$ Dhup V (2011) Public Health Importance of Zoonotic Diseases.

5. WHO (2013) Managing Zoonotic public health risks at the humananimal ecosystem interface. Department of Food Safety and Zoonoses.

6. Tschopp R, Abera B, Sourou SY, Guerne-Bleich E, Aseffa A, et al. (2013) Bovine tuberculosis and brucellosis prevalence in cattle from selected milk cooperatives in Arsi zone, Oromia region, Ethiopia. BMC Veterinary Research 9: 163-6148.

7. USDA (2013) APHIS. Escherichia coli O157 in United States feedlots.

8. Amenu K, Spengler M, Markemann A, Zarate AV (2014) Microbial quality of water in rural households of Ethiopia: implications for milk safety and public health. Journal of Health, Population, and Nutrition 32: 190-197.

9. Tadesse G, Gebremedhin EZ (2015) Prevalence of Salmonella in raw animal products in Ethiopia: a meta-analysis. BMC Research Notes 8: 163.

10. Grace D, Mutua F, Ochungo P, Kruska R, Jones K, et al. (2012) Mapping of poverty and likely zoonoses hotspots. Zoonoses Project 4 , report to Department for International Development, UK. International research Institute.

11. WHO (2010) Managing zoonotic public health risks at the human animal- ecosystem interface. Strong inter-sectoral partnerships in health Food safety and zoonoses.

12. Hiko A, Malicha G (2016) Climate Change and Animal Health Risk. In: Climate Change and the 2030 Corporate Agenda for Sustainable Development, pp: 77-111.

13. Papadopoulos A, Wilmer S (2011) One Health: A Primer. National Collaborating Centre for Environmental Health. J Health Sci 32: 15-19.

14. Islam MA (2014) Zoonoses in Bangladesh: The Role of Veterinarian in Public Health Bangladesh. Journal of Veterinary Medicine 12: 93-98.

15. WHO (2005) The control of neglected zoonotic diseases: a route to poverty alleviation: report of a joint WHO/DFID-AHP with the participation of FAO and OIE. World Health Organization.

16. Chomel BB (2008) Control and prevention of emerging parasitic zoonoses. International Journal for Parasitology 38: 1211-1217.

17. Bassil KL, Cole DC, Smoyer-Tomic K, Callaghan M (2007) What is the Evidence on Applicability and Effectiveness of Public Health Interventions in Reducing Morbidity and Mortality During Heat Episodes?: A Review for the National Collaborating Centre for Environmental Health. NCCEH Vancouver, BC, Canada.

18. Girma SG, Zewde K, Tafess K, Jibat T (2012) Assessment of awareness on food borne zoonoses and its relation with veterinary public health services in and around Addis Ababa, Ethiopia. J Public Health Epi 4: 48-51.

19. Paige SB, Malavé C, Mbabazi E, Mayer J, Goldberg TL (2015) Uncovering zoonoses awareness in an emerging disease 'hotspot'. Social Science and Medicine 129: 78-86.
20. Tesfaye D, Fekede D, Tigre W, Regassa A, Fekadu A (2013) Perception of the public on the common zoonotic diseases in Jimma, Southwestern Ethiopia. School of Veterinary Medicine, Hawassa University, Ethiopia. Int J Med Med Sci 5: 279-285.

21. Tirsit K, Deressa B, Alem F, Tigre W (2013) Farmer's Awareness and Practices on Rabies, Bovine Tuberculosis, Taeniasis, Hydatidosis and Brucellosis in Mana and Limmukosa Districts of Jimma Zone, South West Ethiopia, Jimma University, College of Agriculture and Veterinary Medicine. World Applied Sciences Journal 23: 782-787

22. Chukwunonso F (2016) Herdsmen and Livestock Farmers' Perception, Attitudes and Risk Factors towards Zoonotic Diseases in Awka North and South Local Government Areas, Southeastern Nigeria. Federal College of Education (Technical); School of Agriculture and Home Economics Education. Not Sci Biol 8: 301-305.

23. BAARS (2006) Bureau of Agriculture. Amhara Regional States Bureau of Agriculture and development, Bahir Dar Ethiopia.

24. CSA (2017) Ethiopia-Population and Housing Census 2017 - IPUMS Subset Central Statistical Agency, 2007.

25. Thrusfield M (2005) Veterinary epidemiology. 2nd edn., Blackwell Science, Oxford, pp: 117-198.

26. Dvorak G, Spickler AR, Roth JA (2008) Handbook for zoonotic diseases of companion animals. Center for Food Security and Public Health, Iowa State Unniversity, College of Veterinary Medicine 27: 234-269.

27. Lipton BA, Hopkins SG, Koehler JE, DiGiacomo RF (2008) A survey of veterinarian involvement in zoonotic disease prevention practices. Journal of the American Veterinary Medical Association 233: 1242-1249.

28. Chikerema SM, Matope G, Pfukenyi DM (2013) Awareness and attitude toward zoonoses with particular reference to Anthrax among cattle owners in selected rural communities of Zimbabwe. VBZD 13: 243-249.

29. Fekadu M (1972) A typical rabies in dogs in Ethiopia. J Ethiop Med 10: 79-86.

30. Fekadu M (1982) Rabies in Ethiopia. Am J Epidemiol 115: 266-273.

31. Esayas F, Hiko A, Ali A, Kedir A, Kokorevica L (2012) Infectiousness of brain and salivary gland suspension from rabies suspected dogs. Int $\mathrm{J}$ Public Health Epidemiol 1: 031-034.

32. Swai ES, Schoonman L (2012) A survey of zoonotic diseases in trade cattle slaughtered at Tanga city abattoir: a cause of public health concern. Asian Pacific Journal of Tropical Biomedicine 2: 55.

33. WHO (2015) Managing Zoonotic Public health risks at the human animal ecosystem interface.

34. Hodgson K (2013) One Health- integrating family and veterinary medicine in the community Office of Continuing Education and Professional Development. Faculty of Medicine, University of Toronto, Toronto, Canada.

35. Amenu K, Thys E, Regassa A, Marcotty T (2010) Brucellosis and Tuberculosis in Arsi-Negele District, Ethiopia: Prevalence in Ruminants and People's Behavior towards Zoonoses. J Tropicutura 28: 205-210.

36. OIE (2010) World Animal Health Information Database (WAHID) Interface. World Organization for Animal Health (OIE). 